\title{
Sex Differences in the Effects of Testosterone and Its Metabolites on Vasopressin Messenger RNA Levels in the Bed Nucleus of the Stria Terminalis of Rats
}

\author{
Geert J. De Vries, Zuoxin Wang, Nina A. Bullock, and Suzanne Numan \\ Department of Psychology and Neuroscience and Behavior Program, University of Massachusetts, Amherst, \\ Massachusetts 01003
}

\begin{abstract}
Male rats have about two times as many steroid-responsive vasopressin-immunoreactive (AVP-ir) neurons in the bed nucleus of the stria terminalis (BST) as female rats. This sex difference does not depend on differences in circulating hormone levels, since it persists in males and females that are treated with similar levels of testosterone. To analyze the cellular basis of this sex difference, we compared the effects of testosterone and its metabolites on AVP mRNA expression in the BST of males and females that were gonadectomized at 3 months of age.

When rats received implants of Silastic tubing filled with testosterone, males had more cells that were labeled for AVP mRNA and more labeling per cell than females. When, in a second experiment, rats received implants of either empty tubing, or tubing with dihydrotestosterone (DHT), estradiol (E), or E plus DHT, hardly any labeled cells were found in rats with empty implants. E treatment significantly stimulated AVP mRNA expression in both sexes, but significantly more so in males, which had more cells that were labeled for AVP mRNA and more labeling per cell than females. DHT treatment by itself did not stimulate AVP mRNA expression, but when given in combination with $E$, it significantly increased the number of cells over that of animals treated with E alone. This increase was seen in males only. However, in both sexes, it increased the labeling per cell over that of animals treated with $E$ only, but more so in males than in females. These data suggest that in addition to a sex difference in the number of cells that produce AVP there is also a sex difference in estrogen as well as androgen responsiveness in individual AVP-producing cells in the BST.

[Key words: vasopressin, testosterone, estradiol, dihydrotestosterone, aromatase, sexual dimorphism]
\end{abstract}

In rodents, gonadal hormone levels determine the direction of sexual differentiation of centrally regulated functions and behaviors presumably by targeting specific neuronal systems in a restricted, critical period around birth. Indeed, many structural

\footnotetext{
Received Feb. 24, 1993; revised Sept. 2, 1993; accepted Sept. 14, 1993.

We thank Jeffrey Blaustein, Hussien Al-Shamma, Bradley Crenshaw, and Lei Zhou for critically reading the manuscript, and Lawrence Schwartz for giving technical advice. The research in this article was supported by NIMH Grant RO1 MH47538 to G.J.D.

Correspondence should be addressed to Geert J. De Vries, Department of Psychology, University of Massachusetts, Amherst, MA 01003.

Copyright (C) 1994 Society for Neuroscience 0270-6474/94/141789-06\$05.00/0
}

sex differences have been found in the brain that depend on the sex differences in gonadal steroid levels during development (Yahr, 1988; De Vries, 1990; Breedlove, 1992). An example of such a system is the vasopressin-immunoreactive (AVP-ir) projections of the bed nucleus of the stria terminalis (BS1) to brain areas such as the lateral septum and lateral habenular nucleus. These projections are about twice as dense in males as in females (De Vries et al., 1981; De Vries and Al-Shamma, 1990) and, correspondingly, the BST in males contains about two times as many AVP-ir cells, or cells that can be labeled for AVP mRNA as the BST in females (Van Leeuwen et al., 1985; Miller et al., 1989b). The sex differences in AVP immunostaining of the BST projections remain present even when males and females are treated equally with testosterone (De Vries and Al-Shamma, 1990).

Although the development of this sex difference depends on the presence of gonadal steroids shortly after birth (Wang et al., 1993), it is unclear specifically which cellular features underlie the expression of this difference. In addition to sex differences in the absolute number of cells that can produce AVP, these cells may differ in their responsiveness to gonadal hormones. After gonadectomy, BST cells lose their AVP immunoreactivity and can no longer be labeled for AVP mRNA unless the rats were treated with testosterone (De Vries et al., 1984, 1985; Van Leeuwen et al., 1985; Miller et al., 1989a, 1992). This effect of testosterone appears to depend on androgen as well as estrogen receptor-mediated mechanisms. Estradiol (E) - which is an estrogenic metabolite of testosterone generated by aromatization (Naftolin et al., 1975)-partially restores AVP immunostaining in castrated male rats, while $5 \alpha$-dihydrotestosterone (DIT)which is an androgenic, nonaromatizable metabolite of testosterone generated by reduction (Lieberburg and McFwen, 1975)does not by itself restore AVP immunostaining. However, if DHT is given in combination with $E$, it enhances AVP immunostaining (De Vries et al., 1986). Since male rats have higher levels of aromatase, the enzyme that catalyzes the aromatization of testosterone into $\mathrm{E}$, as well as higher numbers of androgen receptors in the BST than female rats (Roselli, 1991), either of these difference might cause testosterone to stimulate BST cells more effectively in male than in female rats. To explore the possibility that sex differences in the effects of testosterone on AVP mRNA expression may be based on sex differences in the action of its metabolites, we compared the effects of testosterone and its metabolites E and DHT on AVP mRNA expression in the BST of male and female rats. 


\section{Materials and Methods}

In the first experiment, seven adult male and six adult female LongEvans rats (80-90 d old) were gonadectomized and implanted with Silastic tubing $(2.5 \mathrm{~cm}$ long, $1.5 \mathrm{~mm}$ i.d., $2.4 \mathrm{~mm}$ o.d.) filled with testosterone, which previously yielded plasma testosterone levels of 2.4$3.6 \mathrm{ng} / \mathrm{ml}$, which is in the physiological range for males (De Vries et al., 1984). In the second experiment, adult male and female Long-Evans rats (80-90 d old) were gonadectomized and divided into four groups that received either empty implants (controls; seven males and seven females), or implants with $5 \alpha$-dihydrotestosterone (DHT; six males and six females), estradiol (E; six males and eight females), and E plus DHT $(\mathrm{E}+\mathrm{DHT}$; six males and seven females). The dimensions of the Silastic tubing for $\mathrm{E}(1 \mathrm{~cm}$ long, $1 \mathrm{~mm}$ i.d., $2 \mathrm{~mm}$ o.d.) previously yielded plasma levels of $50-90 \mathrm{ng} / \mathrm{ml} \mathrm{E}$, which completely suppressed LH release in males, while the dimensions used for DHT $(3 \mathrm{~cm}, 1.5 \mathrm{~mm}$ and 2.4 $\mathrm{mm}$ o.d.) previously yielded plasma levels of $0.9-1.8 \mathrm{ng} / \mathrm{ml} \mathrm{DHT}$, which fully restored the size of the seminal vesicles in castrated rats (De Vries et al., 1986).

In both experiments, the animals were decapitated 4 weeks after receiving the implants. Their brains were removed, frozen on dry ice, and stored at $-80^{\circ} \mathrm{C}$ until they were cut in $25 \mu \mathrm{m}$ sections with a cryostat. The sections were thaw mounted onto precleaned Superfrost/plus slides (Fisher), which were stored at $-80^{\circ} \mathrm{C}$ until used. The in situ hybridization closely followed a procedure originally developed by Dr. Scott Young (Young et al., 1986) and modified by Drs. Dan Dorsa and Margaret Miller (Miller et al., 1992). Slides were postfixed in 4\% paraformaldehyde for $5 \mathrm{~min}$ and rinsed in $0.1 \mathrm{M}$ phosphate-buffered saline $(\mathrm{pH}$ 7.4) for $2 \mathrm{~min}$, both at $4^{\circ} \mathrm{C}$. The following incubations were done at room temperature: one rinse in $1.5 \%$ triethanolamine (TEA), an incubation in $0.25 \%$ acetic anhydride in TEA (pH 8.0$)$ for $10 \mathrm{~min}$, and two rinses with $0.03 \mathrm{M} \mathrm{Na}$ citrate in $0.3 \mathrm{M} \mathrm{NaCl}(2 \times \mathrm{SSC}), \mathrm{pH} 7.0$. The sections were subsequently defatted in a graded ethanol series, 2 min each in $70 \%, 95 \%$, and $100 \%$ ethanol; $5 \mathrm{~min}$ in chloroform; $2 \mathrm{~min}$ each in $100 \%$ and $95 \%$ ethanol, after which the sections were air dried. Each slide was placed horizontally and after applying $55 \mu \mathrm{l}$ of hybridization solution, the slides were covered with silanized coverslips and placed in a humidified incubator for $14 \mathrm{hr}$ at $37^{\circ} \mathrm{C}$. For the first experiment, the hybridization solution contained $0.8 \times 10^{6} \mathrm{dpm}$ of an oligodeoxyribonucleotide antisense probe that contained 48 bases and was complementary to the AVP mRNA sequence coding for amino acids 129144 , which are located at the carboxyl end of the glycopeptide region of the AVP precursor peptide. For the second experiment it contained $1.2 \times 10^{6} \mathrm{dpm}$ of the probe. The probe was labeled at the $3^{\prime}$-end with ${ }^{35}$ S-dATP (New England Nuclear) using terminal deoxynucleotidyl transferase (Life Technologies Inc.), purified on a Nen-Sorb column (New England Nuclear), and heat denatured prior to mixing it with the rest of the hybridization buffer, which contained $50 \%$ formamide, $4 \times$ SSC, $1 \times$ Denhardt's solution, $2.5 \mathrm{mg} / \mathrm{ml}$ yeast tRNA, $10 \%$ dextran sulfate $(\mathrm{MW}=500,000), 0.3 \mathrm{M} \mathrm{NaCl}, 10 \mathrm{~mm}$ Tris, and $10 \mathrm{~mm}$ dithiothreitol. After incubation, the coverslips were removed by submersing the slides in $1 \times$ SSC, and the slides were rinsed $4 \times 15 \mathrm{~min}$ in $1 \times \mathrm{SSC}$ at $55^{\circ} \mathrm{C}$, and $2 \times 60 \mathrm{~min}$ in $1 \times \mathrm{SSC}$ at room temperature. The sections were then dehydrated through a graded series of $70 \%, 95 \%$, and $100 \%$ ethanol and air dried. To reduce RNase activity, all solutions were prepared with sterile $\mathrm{H}_{2} \mathrm{O}$ that had been treated with $0.1 \%$ diethylpyrocarbonate and autoclaved, and all glassware was baked at $250^{\circ} \mathrm{C}$ for $12 \mathrm{hr}$. Controls on the specificity included treating the sections with ribonuclease A (Sigma), which eliminated labeling; hybridizing sections with a sense probe, which did not produce any labeling; and rinsing the sections in $75^{\circ} \mathrm{C}$ and $90^{\circ} \mathrm{C}$, which greatly diminished and eliminated labeling, respectively.

To locate the probe, the slides were dipped in Kodak NTB-2 track emulsion (1:1 with $0.6 \mathrm{M}$ ammonium acetate, $\mathrm{pH} 3.5)$ under safelight, and stored desiccated in light-tight boxes at $4^{\circ} \mathrm{C}$. Four weeks later, the slides were developed with D19 (Kodak; 1:1 with distilled water) and fixed with Kodak Rapid Fix, rinsed in distilled water followed by 0.1 $\mathrm{M} \mathrm{Na}$ acetate, $\mathrm{pH} 3.5$, lightly counterstained with $0.2 \%$ cresyl violet in $0.1 \mathrm{~m}$ acetate buffer, dehydrated with a graded ethanol series followed by xylene, and coverslipped.

Sections were studied with a Zeiss Axioscope with a Darklite darkfield attachment (MicroVideo Instruments, Inc., Avon, MA). This attachment guides light from a central source via two fiber optic cables, which are flattened at the end to match the right- and left-hand ends of the slide. Because the light enters from the side, much of it is contained in the slide by total reflection and is only dispersed if it encounters silver grains. This gives a much brighter image of the silver grains than what can be obtained with a standard dark-field condenser. AVP mRNAlabeled cells were examined in 14 sections through the BST. Labeled cells were identified in dark-field illuminated slides, and only counted if bright-field illumination revealed a Nissl-stained cell and if the number of grains was at least four times higher than background. For each subject and for each side of the brain, the number of AVP mRNAlabeled cells in the section with most labeled cells were used for data analysis. Grains were counted using dark-field illumination in the section that contained most AVP mRNA-labeled cells. Images of labeled cells were obtained with the $40 \times$ objective and a CCD 72 camera (Dage, MTI, Michigan City, IN) connected to a QuickCapture frame grabber board (Data Translation Inc., Marlboro, MA) in a Macintosh IIfx computer, and analyzed using the IMAGE version 1.44 program developed by Dr. Rasbaud from NIH, Bethesda, MD. The light intensity and camera setting were kept constant across the sections in order to standardize measurements. Grains were counted by computerized gray-level thresholding (Shipley et al., 1989), which determined the number of pixels representing images of grains in an area representing a circle with a diameter of $33 \mu \mathrm{m}$ centered over the cell. The number of pixels was converted into number of grains using a linear regression curve that was obtained by correlating number of pixels with number of grains that were counted individually in 46 cells with grain counts ranging from 2 to 141 . This gave a correlation coefficient of $r=0.99$. The in situ hybridization and the analysis of the sections were done by experimenters that were blind to the identity of the specimens.

The data were analyzed by a two-way analysis of variance (ANOVA) with sex as a between-subject variable and side of the brain as a repeated measure for the first experiment, and by a three-way ANOVA with sex and treatment as between-subject variables and side as a repeated measure for the second experiment. Significant interactions of treatment and sex were further evaluated using the Newman Keuls post hoc test.

\section{Results}

\section{Effects of testosterone on AVP MRNA in males and females}

After receiving similar implants of testosterone, male rats had more AVP mRNA-labeled cells in the BST (Figs. 1, 2; ANOVA, $F=12.43, \mathrm{df}=1 / 11, p<0.01)$, and more grains per labeled cell (Fig. 3; ANOVA, $F=6.63$, df $=1 / 11, p<0.05$ ) than female rats. No significant differences were found in the labeling between the left and right side of the brain.

\section{Effects of testosterone metabolites on AVP MRNA in males and females}

Overall, male rats had more $\Lambda$ VP mRNA-labeled cells in the BST than female rats (ANOVA, $F=16.98$, df $=1 / 45, p<$ $0.0005)$. In addition, the various hormonal treatments significantly affected the number of labeled cells (ANOVA, $F=114.32$, $\mathrm{df}=3 / 45, p<0001)$. These treatment effects, however, differed for males and females (Fig. 4; ANOVA, $F=8.43$, df $=3 / 45, p$ $<0.0001)$. The post hoc Newman Keuls test indicated that E-treated males and females had significantly more AVP mRNAlabeled cells than males and females given empty tubing or tubing with DHT. E-treated males, however, showed significantly more labeled cells than E-treated females. Furthermore, if males were treated with $\mathrm{E}+\mathrm{DHT}$, they showed significantly more cells than males treated with E only. However, females treated with E+DHT did not show more cells than females treated with E only. No significant differences were found in the number of labeled cells between the left and right side of the brain.

Since treatment with empty tubing or with DHT resulted in a loss of virtually all labeled cells in males as well as females, analysis of the number of grains over cells was done only in E-treated and E+DHT-treated animals. In these two groups, male rats showed more grains per labeled cell in the BST than females (Fig. 5; ANOVA, $F=14.93$, df $=1 / 23, p<0.001$ ). In 

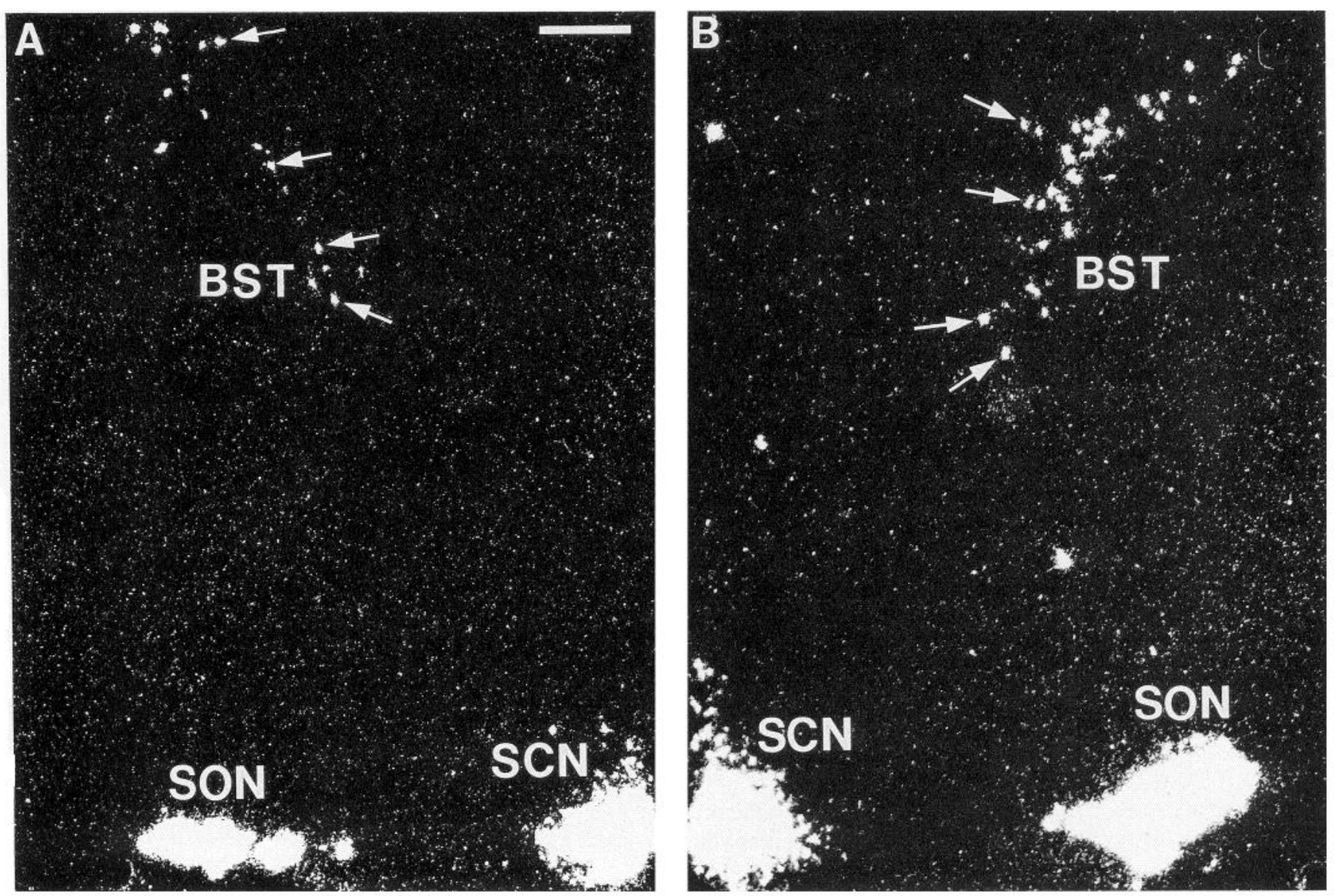

Figure 1. Photomicrographs of dark-field illuminated sections displaying cells labeled for AVP mRNA (arrows) in the BST of a female (A) and a male $(B)$ treated with testosterone. The figure also displays labeled cells in the supraoptic nucleus $(S O N)$ and the suprachiasmatic nucleus $(S C N)$. Scale bar, $100 \mu \mathrm{m}$.

addition, E+DHT-treated rats had more grains per cell than E-treated rats (Figs. 5, 6; ANOVA, $F=6.46$, df $=1 / 23, p<$ $0.05)$. Although the E+DHT treatment seemed to elevate the grain density specifically in males, the interaction of sex and treatment failed to reach significance (ANOVA, $F=3.82$, $\mathrm{df}=$ $1 / 23, p=0.063)$. No significant differences were found in the

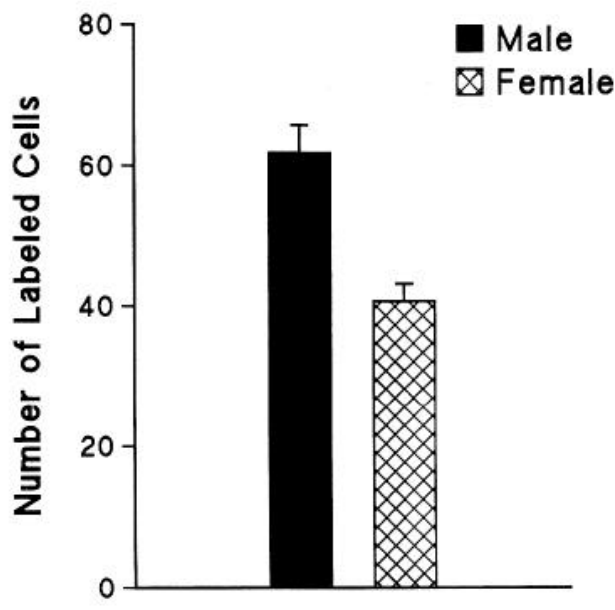

Figure 2. Differences in the number of BST cells labeled for AVP mRNA in male (solid bars) and female rats (crosshatched bars; ANOVA, $p<0.01)$. Bars indicate means \pm SEM. number of grains per cell between the left and right side of the brain.

In the suprachiasmatic, supraoptic, and paraventricular nuclei, the number of labeled cells and the grain density per cell could not be determined accurately. In the suprachiasmatic nucleus, counting cells and grains over cells was impossible because

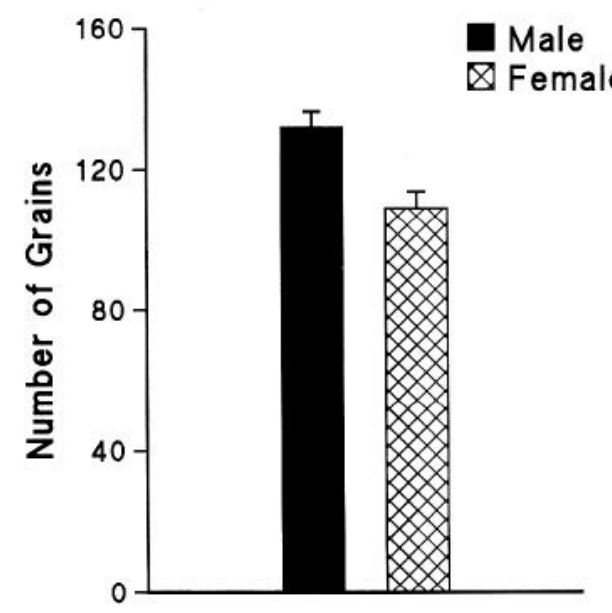

Figure 3. Differences in the number of grains per BST cell labeled for AVP mRNA in male (solid bars) and female rats (crosshatched bars; ANOVA, $p<0.05$ ). Bars indicate means \pm SEM. 


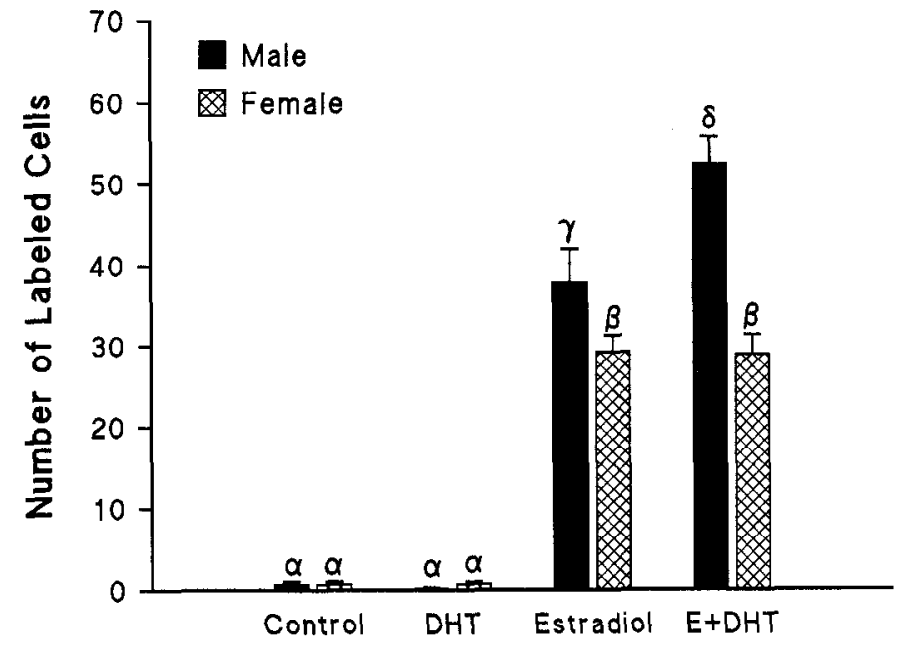

Figure 4. Differences in the number of BST cells labeled for AVP mRNA in male (solid bars) and female rats (crosshatched bars) that were castrated (Control), or castrated and treated with dihydrotestosterone $(D H T)$, estradiol, or a combination of estradiol and DHT $(E+D H T)$. These treatments had different effects in male and female rats (ANOVA, $p<0.0001$ ). The Greek letters illustrate the results of the Newman Keuls post hoc test, which indicated that control and DHT-treated animals had fewer labeled cells than estradiol- or E+DHT-treated females, which in turn had less cells than estradiol-treated males. E+DHTtreated males had more cells than any other group. Bars indicate means \pm SEM.

the density of AVP cells caused the grains generated by different cells to overlap, while in the paraventricular and supraoptic nuclei the grain density per cell was too high to be measured reliably. None of these nuclei, however, showed any notable differences among the different hormonal conditions.

\section{Discussion}

If treated with similar amounts of testosterone, male rats show more AVP-ir cells in the BST and denser AVP-ir projections from the BST to areas such as the lateral septum and lateral habenular nucleus than female rats (De Vries and Al Shamma, 1990). The results of the present study show that, under similar

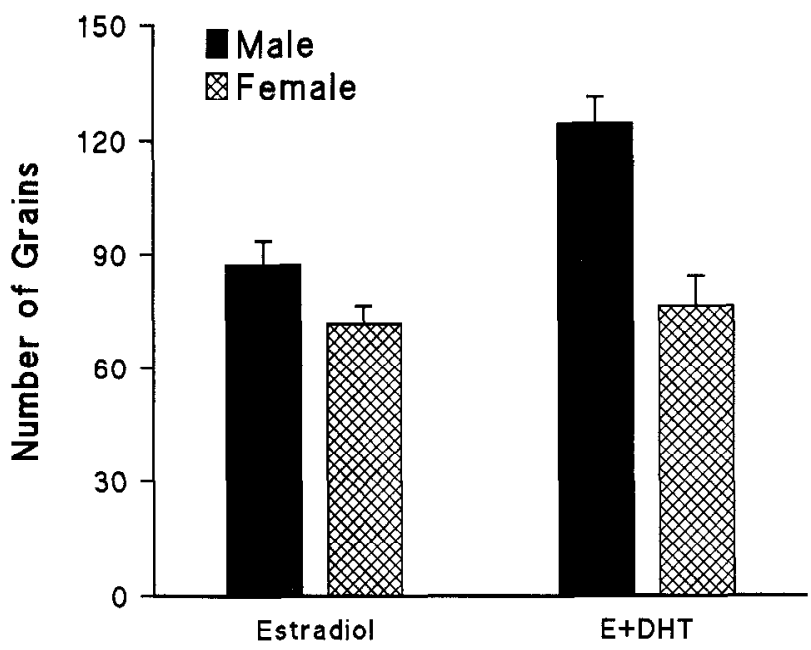

Figure 5. Differences in the number of grains per BST cell labeled for AVP mRNA in male (solid bars) and female rats (crosshatched bars) that were treated with estradiol or a combination of estradiol and dihydrotestosterone $(E+D H T)$.
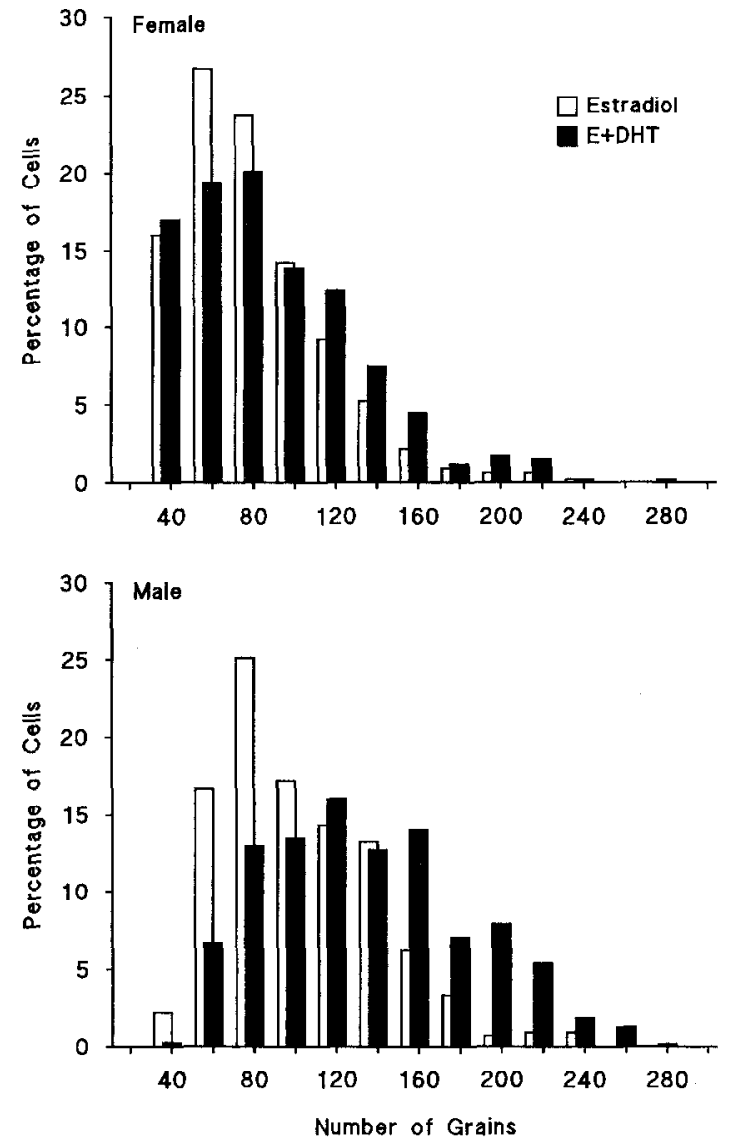

Figure 6. Frequency distributions of BST cells according to the density of their AVP mRNA labeling in female (top) and male rats (bottom) treated with estradiol (open bars) or estradiol and dihydrotestosterone $(E+D H T$, solid bars $)$.

hormonal conditions, males also show more BST cells that can be labeled for AVP mRNA and more labeling per cell than females. Furthermore, they show that there are sex differences in the responsiveness of individual BST cells to testosterone metabolites, in particular to DHT, which if given in combination with $E$ increased the number of AVP mRNA-labeled cells in males but not in females. The possibility that sex differences in hormone metabolism and in the levels and actions of estrogen and androgen receptors contribute to these differences will be discussed.

A previous study comparing AVP mRNA labeling in three intact males and three intact temales had suggested that males have more BST cells that can be labeled for AVP mRNA and more grains per labeled cell than females have (Miller et al., $1989 \mathrm{~b}$ ): Since, in males, AVP mRNA labeling of individual BST cells reacts within a day to a reduction in gonadal hormone levels (Miller et al., 1992), the sex differences in AVP mRNA labeling reported by Miller et al. (1989b) could have been caused by sex differences in gonadal hormone levels. The present study, however, shows that sex differences in AVP mRNA labeling of BST cells remain present even if males and females are treated with similar amounts of testosterone, suggesting that sex differences in AVP mRNA labeling in intact animals cannot be explained merely by differences in circulating hormones.

Sex differences in the interaction of gonadal hormones and AVP cells in the BST could have contributed to the sex differences in AVP mRNA labeling observed in the present study. 
For tcstostcronc, this intcraction appcars to involve androgen as well as estrogen receptor-mediated mechanisms. Previously we had found that, in castrated male rats, E increases the levels of AVP immunoreactivity, but not to the same extent as testosterone does. DHT, when given in a dose that restores the size of the seminal vesicles, does not influence AVP immunoreactivity by itself, but when given in combination with $E$, it restores AVP immunoreactivity to levels reached after testosterone treatment (De Vries et al., 1986). The present study shows that, in castrated males, the effects of $E$ and DHT on AVP mRNA expression are similar to their effects on AVP immunoreactivity. When given by itself, $E$ increased the number of cells that were labeled for AVP mRNA as well as the level of AVP mRNA labeling per cell, while DHT when given by itself did not influence either. However, when given in combination with $\mathrm{E}, \mathrm{DHT}$ did increase the number of AVP mRNA-labeled cells. Recently, we have found that local application of DHT in the brain of castrated rats can moderately elevate AVP mRNA labeling in the BST, suggesting that central actions of DHT may depend on its concentration (Brot et al., 1993).

Since testosterone has to be aromatized into $\mathrm{E}$ before it can influence estrogen receptors (Lieberburg and McEwen, 1975; Naftolin et al., 1975), the higher levels of aromatase found in the BST of males (Roselli, 1991) suggest that under similar testosterone treatment AVP-producing cells in the BST of males may be exposed to higher levels of $E$ than similar cells in the BST of females. However, since males had still more AVP mRNA-labeled cells and more grains per labeled cell than females after receiving similar $E$ treatment, the sex differences in AVP mRNA labeling cannot be explained merely by sex differences in the conversion of testosterone into E. Rather, more BST cells in males respond to estrogen stimulation than in females. The slightly higher proportion of labeling per cell in E-treated males than in E-treated females suggests that there are also sex differences in estrogen responsiveness of individual AVP-producing cells.

Even more so than differences in estrogen responsiveness, sex differences in androgen responsiveness appear to contribute to sex differences in AVP-producing cells in the BST. When given in combination with E, DHT increased the number of AVP mRNA-labeled cells in males but not at all in females. These sex differences in steroid responsiveness may be based on sex differences in inputs that are responsive to gonadal hormones. There are, for example, sex differences in the substance $P$ and cholecystokinin innervation of the BST, both of which are responsive to testosterone and E (Malsbury and McKay, 1987; Simerly and Swanson, 1987; Micevych et al., 1988; Oro et al., 1988). It is unknown, however, whether these inputs influence AVP production in the BST. Alternatively, sex differences in steroid responsiveness of AVP-producing cells in the BST may be based on differences in androgen and estrogen receptors within these cells, since virtually all them are immunoreactive for androgen and estrogen receptors (Axelson and Van Leeuwen, 1990; Zhou et al., 1993). Although no sex differences have been found in the number of estrogen receptors in the BST (Brown et al., 1988, 1992), there are indeed sex differences in the number of androgen receptors associated with the cell nuclear fraction of the BST (Roselli, 1991). Such sex differences in androgen receptors could explain why DHT acts on AVP mRNA labeling in males but not in females.

In addition to sex differences in steroid-sensitive neuronal inputs or in steroid receptors levels, sex differences in the in- teractions of occupied gonadal steroid receptors may contribute to sex differences in AVP-producing cells in the BST. For example, since androgen enhances BST aromatase levels in males more than in females (Roselli et al., 1985a,b; Roselli, 1991), testosterone may enhance its own conversion into $\mathrm{E}$ and therefore its actions on AVP mRNA expression in males more than in females. This particular androgen effect, however, cannot explain the sex differences in the effects of DHT on AVP mRNA in E-treated animals, since these animals were exposed to similar levels of $\mathbf{E}$. Another possibility is that estrogen increases the responsiveness of individual cells to androgen in males more than in females. For example, E might prevent the metabolic inactivation of DHT in the brain (Södersten, 1980). E might also increase the effectiveness of androgen receptors of AVP. producing cells by altering the duration of androgen receptor occupation, as has been observed in the preoptic area of male rats (Roselli and Fasasi, 1992). It is unknown, however, whether there are any sex differences in these actions of E. Finally, there may be sex differences in the interaction of gonadal steroid receptors and the AVP gene. Since there are no clearly recognizable androgen- and estrogen-responsive elements on the promoter region of the AVP gene (Adan and Burbach, 1992; Young, 1992), the nature of this interaction is unclear.

The sex differences found in the present study suggest that sexual differentiation of AVP projections of the BST entails a number of developmental decisions, among which a decision as to how many BST cells will express AVP and a decision on the efficacy of the mechanisms that mediate gonadal hormone effects on AVP gene expression in individual cells. A recent study suggests that these decisions depend on differences in the levels of gonadal hormones in the first weeks after birth (Wang et al., 1993). Interestingly, the latter study indicated that the decision as to how many cells will express AVP depends largely on hormonal differences in the second week after birth, whereas the decision as to how dense the AVP-ir fiber plexus will bewhich may reflect absolute number as well as AVP content of individual fibers-depends on hormonal differences in the first as well as second week after birth. Such a discrepancy can indeed be explained by sexual differentiation of several cellular features that together contribute to the sexually dimorphic nature of AVP-producing cells in the BST.

AVP projections of the BST are probably involved in social recognition memory, temperature regulation, and aggressive behavior (Pittman et al., 1988; Bluthé et al., 1990; Koolhaas et al., 1990), and presumably in osmoregulation and reproductive functions (Epstein et al., 1983; Demotes-Mainard et al., 1986; Bamshad et al., 1993). Therefore, studying how steroid hormones influence these projections will help clarify how hormones induce and maintain the sex differences that have been found in several of these behaviors and functions (Dantzer and Bluthé, 1992; De Vries et al., 1992). The extreme nature of the sex differences in, and hormonal effects upon, these projections will undoubtedly help in this pursuit.

\section{References}

Adan RAH, Burbach JPH (1992) Regulation of vasopressin and oxytocin gene expression by estrogen and thyroid hormone. Prog Brain Res 92:127-136.

Axelson JF, Van Leeuwen FW (1990) Differential localization of estrogen receptors in various vasopressin synthesizing nuclei of the rat brain. J Neuroendocrinol 2:209-216.

Bamshad M, Novak MA, De Vries GJ (1993) Sex and species differ- 
ences in the vasopressin innervation of sexually naive and parental prairie voles, Microtus ochrogaster and meadow voles, Microtus pennsylvanicus. J Neuroendocrinol 5:247-255.

Bluthe RM, Schoenen J, Dantzer R (1990) Androgen-dependent vasopressinergic neurons are involved in social recognition in rats. Brain Res 519:150-157.

Breedlove SM (1992) Sexual dimorphism in the vertebrate nervous system. J Neurosci 12:4133-4142.

Brot MD, DeVries GJ, Dorsa DM (1993) Local implants of testosterone metabolites regulate vasopressin mRNA in sexually dimorphic nuclei of the rat brain. Peptides 14:933-941.

Brown TJ, Hochberg RB, Zielinski JE, MacLusky NJ (1988) Regional sex differences in cell nuclear estrogen-binding capacity in the rat hypothalamus and preoptic area. Endocrinology 123:1761-1770.

Brown TJ, Naftolin F, Maclusky NJ (1992) Sex differences in estrogen receptor binding in the rat hypothalamus: effects of subsaturating pulses of estradiol. Brain Res 578:129-134.

Dantzer R, Bluthé RM (1992) Vasopressin involvement in antipyresis, social communication, and social recognition: a synthesis. Crit Rev Neurobiol 16:243-255.

Demotes-Mainard J, Chauveau J, Rodriguez F, Vincent JD, Poulain DA (1986) Septal release of vasopressin in response to osmotic, hypovolemic and electrical stimulation in rats. Brain Res 381:314321.

De Vries GJ (1990) Sex differences in neurotransmitters in the brain. J Neuroendocrinol 2:1-13.

De Vries GJ, Al-Shamma HA (1990) Sex differences in hormone sensitivity of vasopressin pathways in the rat brain. J Neurobiol 21 : 686-693.

De Vries GJ, Buijs RM, Swaab DF (1981) Ontogeny of the vasopressinergic neurons of the suprachiasmatic nucleus and their extrahypothalamic projections in the rat brain-presence of a sex difference in the lateral septum. Brain Res 218:67-78.

De Vries GJ, Buijs RM, Sluiter AA (1984) Gonadal hormone actions on the morphology of the vasopressinergic innervation of the adult rat brain. Brain Res 298:141-145.

De Vries GJ, Buijs RM, Van Leeuwen FW, Caffe AR, Swaab DF (1985) The vasopressinergic innervation of the brain in normal and castrated rats. J Comp Neurol 233:236-254.

De Vries GJ, Duetz W, Van Heerikhuize J, Buijs RM, Vreeburg JTM (1986) Androgen and estrogen influences on the vasopressinergic innervation of the rat brain. Brain Res 399:296-302.

De Vries GJ, Crenshaw BD, Al-Shamma HA (1992) Oxytocin in maternal, sexual, and social behaviors. Gonadal steroid modulation of vasopressin pathways. Ann NY Acad Sci 652:387-396.

Epstein YM, Caster SM, Glick N, Sivan N, Ravid R (1983) Changes in hypothalamic and extrahypothalamic vasopressin content of waterdeprived rats. Cell Tissue Res 233:99-111.

Koolhaas JM, Van den Brink THC, Roozendaal B, Boorsma F (1990) Medial amygdala and aggressive behavior: interaction between testosterone and vasopressin. Aggressive Behav 16:223-229.

Lieberburg I, McEwen BS (1975) Brain cell nuclear retention of testosterone metabolites $5 \alpha$-dihydrotestosterone and estradiol- $17 \beta$ in adult rat. Endocrinology 100:588-597.

Malsbury CW, McKay K (1987) Sex differences in the pattern of substance P-like immunoreactivity in the bed nucleus of the stria terminalis. Brain Res 420:365-370.

Micevych PE, Akesson T, Elde R (1988) Distribution of cholecystokinin-immunoreactive cell bodies in the male and female rat. II. Bed nucleus of the stria terminalis and amygdala. J Comp Neurol 269: 381-391.
Miller MA, Urban JA, Dorsa DM (1989a) Steroid dependency of vasopressin neurons in the bed nucleus of the stria terminalis by in situ hybridization. Endocrinology 125:2335-2340.

Miller MA, Vician L, Clifton DK, Dorsa DM (1989b) Sex differences in vasopressin neurons in the bed nucleus of the stria terminalis by in situ hybridization. Peptides 10:615-619.

Miller MA, De Vries GJ, Al-Shamma HA, Dorsa DM (1992) Rate of decline of vasopressin immunoreactivity and messenger RNA levels in the bed nucleus of the stria terminalis. J Neurosci 12:2881-2887.

Naftolin F, Ryan KJ, Davies IJ, Reddy VV, Flores F, Petro D, Kuhn M, White RJ, Takaota Y, Wolin L (1975) The formation of estrogens by central neuroendocrine tissue. Rec Prog Horm Res 31:295-316.

Oro AE, Simerly RB, Swanson LW (1988) Estrous cycle variations in levels of cholecystokinin immunoreactivity within cells of three in terconnected sexually dimorphic forebrain nuclei. Neuroendocrinology 47:225-235.

Pittman QJ, Malkinson TJ, Kasting NW, Veale WL (1988) Enhanced fever following castration: possible involvement of brain arginine vasopressin. Am J Physiol 254:R513-R517.

Roselli CE (1991) Sex differences in androgen receptors and aromatase activity in microdissected regions of the rat brain. Endocrinology 128 : 1310-1316.

Roselli CE, Fasasi TA (1992) Estradiol increases the duration of nuclear androgen receptor occupation in the preoptic area of the male rat treated with dihydrotestosterone. J Steroid Biochem Mol Biol 42: 161-168.

Roselli CE, Horton LE, Resko JA (1985a) Distribution and regulation of aromatase activity in the rat hypothalamus and limbic system. Endocrinology 117:2471-2477.

Roselli CE, Horton LE, Resko JA (1985b) Time course and steroid specificity of aromatase induction in rat hypothalamus-preoptic area. Biol Rcprod 37:628-633.

Shipley MT, Luna J, McLean JH (1989) Processing and analysis of neuroanatomical images. In: Neuroanatomical tract tracing methods 2 (Heimer L, Záborsky L, eds), pp 331-390. New York: Plenum.

Simerly RB, Swanson LW (1987) Castration reversibly alters levels of cholecystokinin immunoreactivity within cells of three interconnected sexually dimorphic forebrain nuclei in the rat. Proc Natl Acad Sci USA 84:2087-2091.

Södersten P (1980) A way in which oestradiol might play a role in the sexual behaviour of male rats. Horm Behav 14:271-274.

Van Leeuwen FW, Caffé AR, De Vries GJ (1985) Vasopressin cells in the bed nucleus of the stria terminalis of the rat sex differences and the influences of androgens. Brain Res 325:391-394.

Wang ZX, Bullock NA, De Vries GJ (1993) Sexual differentiation of vasopressin projections of the bed nucleus of the stria terminalis and medial amygdaloid nucleus in rats. Endocrinology 132:2299-2306.

Yahr P (1988) Sexual differentiation of behavior in the context of developmental psychobiology. In: Handbook of behavioral neurobiology, Vol 9 (Blass EM, ed), pp 197-243. New York: Plenum.

Young WS III (1992) Expression of the oxytocin and vasopressin genes. J Neuroendocrinol 4:527-540.

Young WS III, Bonner TI, Brann MR (1986) Mesencephalic dopamine neurons regulate the expression of neuropeptide mRNAs in the rat forebrain. Proc Natl Acad Sci USA 83:1685-1694.

Zhou L, Blaustein JD, De Vries GJ (1993) Distribution of androgen receptor immunoreactivity in vasopressin- and oxytocin-immunoreactive neurons in the rat brain. Soc Neurosci Abstr 19: 1558 . 